\title{
Innovative Application Technologies of AC Motor Drive Systems
}

\author{
Keiichiro Kondo $^{* a)}$ Senior Member, Hisao Kubota ${ }^{* *}$ Senior Member
}

(Manuscript received March 13, 2012, revised June 20, 2012)

\begin{abstract}
This paper deals with the innovative application technologies on variable speed AC motor drive systems. These application technologies are categorized on the basis of the advantages of the AC variable speed motor drive systems, such as downsizing, packaging with high density, energy savings, better availability and maintenancebility, higher controllability of the torque and speed, load leveling. Various component technologies such as the power conversion technology, control technology, and motor technology are also mentioned along with their related application technologies. Future perspectives of the ac drive application technologies are discussed in the conclusion of the paper.
\end{abstract}

Keywords: AC variable speed dive, PMSM drive, IM drive, power converter, motor control

\section{Introduction}

Electrical and mechanical energy conversion system has many advantages against the other measures to obtain the mechanical force, such as internal combustion engines and hydraulic actuators. In the electrical motor drive, variable speed ac motor drive system has been developed thanks to the progress of the power electronics technologies. Inverterdriven induction motors can be controlled more precisely than dc motor drive system thanks to the field-oriented control. Inverter-driven permanent magnet synchronous motors can increase their efficiency and can reduce their mass and dimensions, compared with induction motors. Brushes and commutaters in dc motors require the periodical inspection and replacement, and limit current change ratio against time. Variable speed ac motor drive systems are free from the any technical problems with the brushes and commutaters. The wider speed operation range than the dc motor and regenerative brake operation with unity power factor at the front end are other advantages of the ac motor drive system. In early 1990's, the rare earth magnet released in the market and started to apply permanent magnet synchronous motors (PMSMs) to the various power range up to around $1 \mathrm{MW}$. PMSMs play important roles in the application field where the higher efficiency and/or the downsizing are preferred or required. Thanks to the progress of the power semiconductor devices technologies in these 20 years, such as the IGBTs in 1990's and SiC devices in 2000's, power electronics technologies have been expanding their application fields. The progress of the power electronics also promotes the application or variable speed ac motor drive technologies.

Ac drive systems provide the various engineering benefits compared with the other measures to obtain the mechanical force. Figure 1 shows that technical features and benefits of

\footnotetext{
a) Correspondence to: Keiichiro Kondo. E-mail: kkondo@faculty. chiba-u.jp

* Engineering Dept., Graduate School of Chiba University 1-33, Yayoi-cho, Inage-ku, Chiba 258-8540, Japan

** School of Science and Technology, Meiji University

1-1-1, Higashi-mita, Tama-ku, Kawasaki 214-8571, Japan
}

ac motor drive systems ontheir applications. Technical benefits of the applications of ac motor drive systems are,

- more downsizing and more packaging,

- more precise control of the torque and the speed,

- higher availability and higher maintenancebility,

- energy savings,

- and load leveling with the energy storage devices.

After the progress of the ac drive systems themselves including power electronics technologies, they are combined with the energy storage devices such as batteries or capacitors to carry out bidirectional energy conversion between the electric energy and the mechanical energy. ac drive systems play new role as an essentialcomponents of sub-system in the emerging applications to save the energy. This fact indicates one of the directions of future progress of ac motor variable speed drive technologies. This paper aims at revealing the direction of the development of the ac drive systems, through the reviewing the recent innovative ac drive applications.

In the first part of this paper, innovative ac drive applications are categorized by the benefits of the applications as mentioned above. Some of the examples of the application in the each technical benefit are introduced and reviewed in each section. In addition, some of the essential technologies in the motor itself, power conversion circuit and motor control are mentioned in each section. Through the review of the recent innovative applications, future progress of the ac motor variable drive system is discussed in the last part of the paper.

\section{Applications for More Precise Torque and Speed Control}

2.1 Principal of More Precise Torque and Speed Control of the AC Drive System Torque of electrical motors principally can be controlled more precisely than the one of internal combustion engines can be done because the current and flux is easier to control. Thanks to the field-oriented control and the brush less structure, ac motor drive systems can provide higher torque response than dc motor drive systems. The higher torque control capability can improve the speed control capability and can provide additional technical 


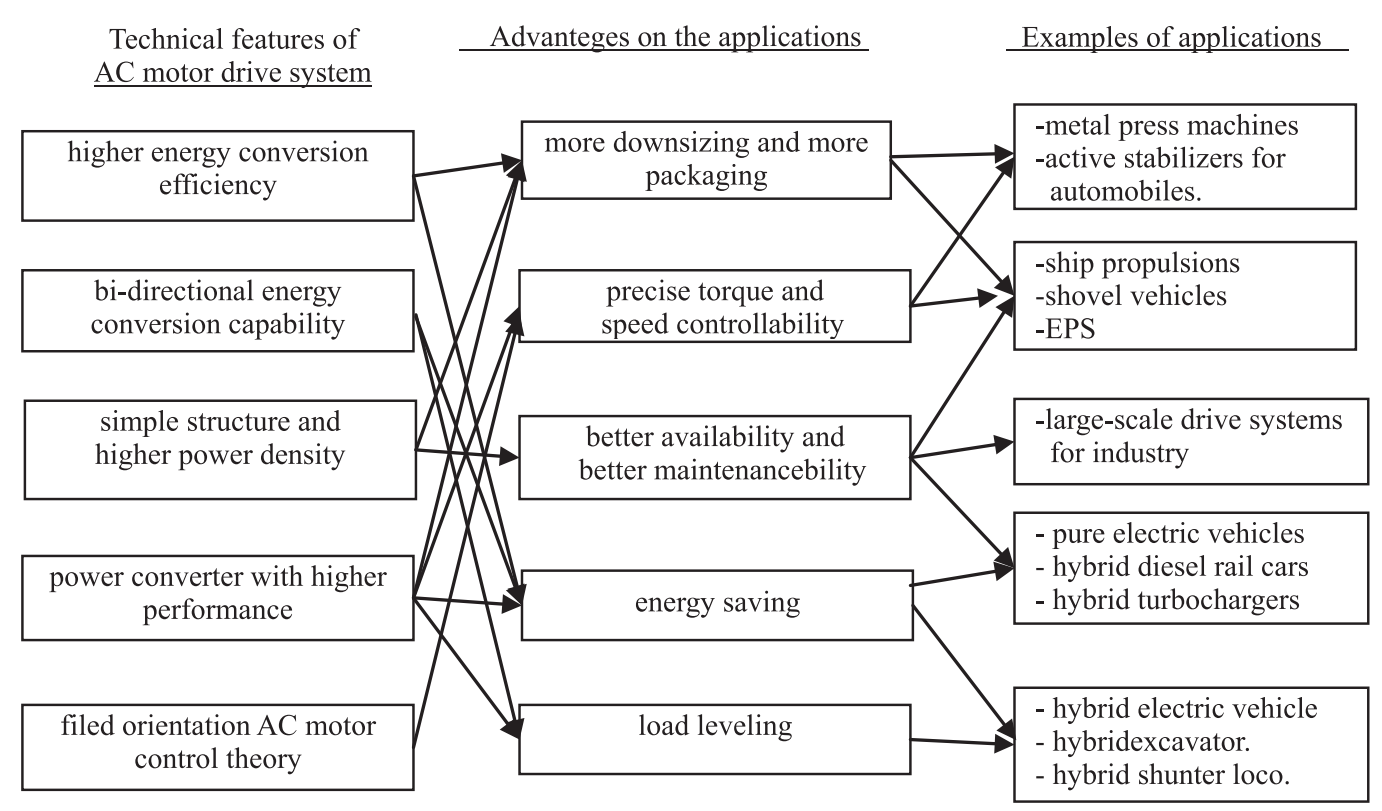

Fig. 1. Technical features of variable speed AC motor drive systems and their applications

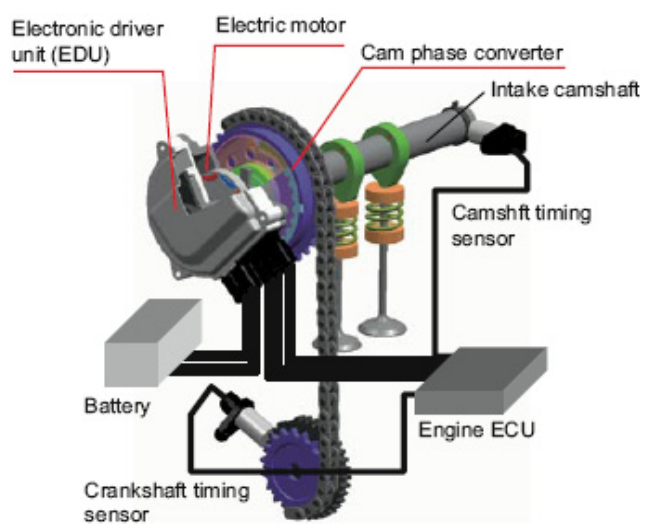

Fig. 2. Configuration of electric variable valve timing control system ${ }^{(2)}$

\section{benefits.}

\subsection{Large Scale Servo Drive for Electric Press Ma-}

chines Large scale electric press machines, for instance for producing automobile parts, can enhance the press force and improve their controllability by applying a $100 \mathrm{~kW}$ class servo drive system and a wheel with high inertia. The electric press machines are able to control the press force and speed more precisely than the hydraulic press machines. These feature enable to reduce the noise and vibration during the press process with precisely controlling the press force ${ }^{(1)}$. By combining with a wheel with higher inertia, the electric press machine can process the material which is hard to be processed with higher precision.

2.3 Servo Controls and Precise Torque Controls for Automobile Applications In addition to the electrical propulsion system of the pure electrical vehicles or hybrid electric vehicles, ac motor servo controls are applied to the auxiliary equipments of the conventional type automobiles with internal combustion engine. One of the examples is an electric variable valve timing control system, as shown in Fig. 2, for an internal combustion engines ${ }^{(2)}$. A down sized IPMSM is installed on the axle of the cam shaft. The ac servo

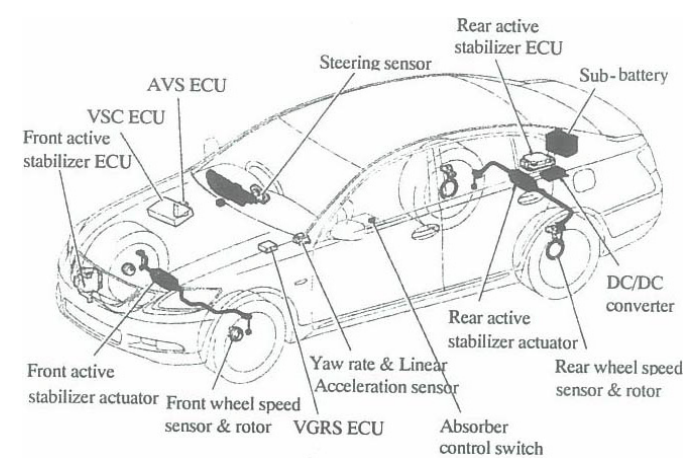

Fig. 3. Electric active stabilizer suspension system ${ }^{(5)}$

drive can open and close the intake and exhaust valves at the optimal timing for each, independent from the engine crank shaft angle and speed. Thus, the engine output power is enhanced in wider speed range than the one of the conventional mechanical variable valve timing system. These functions are achieved by the feature of the higher power density of the electric motor and higher controllability of the ac servo system.

An electric active stabilizer suspension as shown in Fig. $3^{(3)}$, is another application of servo controllers for the automobile. The torsion torque is controlled by an ac servo motor to reduce the roll angle of the vehicle body, which enhances the drivability and improve the stability of the car body during the vehicle's curving.

Test benches such as the dynamometers ${ }^{(4)}$ are examples of precise torque control for the automobile. In the applications, the current control system has a dynamic range of $1500 \mathrm{~Hz}$ by compensating the time lag in the current regulator ${ }^{(5)}$. This feature enables to emulate the engine motion caused by the combustion.

2.4 Torque Control Method under the Limited Current and Voltage In the application field of ac variable speed drive, their operational ranges are enlarged in higher torque and higher speed both. Thus, more torque is required 


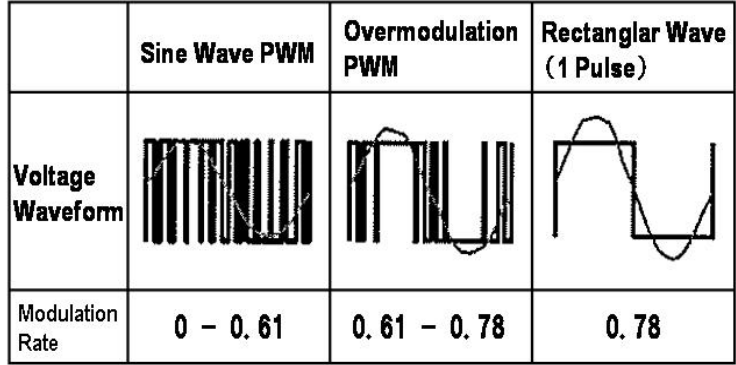

Fig. 4. Voltage waveform of PWM and single-pulse modes $^{(7)}$

even in higher speed range. Higher inverter output voltage and optimized field weakening control are effective to enhance the torque performance in the higher speed range. As an example of the former case, single-pulse mode has been applied to the railway vehicle traction inverters to drive both induction motors and PMSMs for the sake of reducing the switching loss ${ }^{(6)}$. Though this is originated from the railway vehicle traction application, the single plus mode (rectangular wave mode) is applied to a hybrid automobile traction, as shown in Fig. $4^{(7)}$, mainly to enhance the output voltage of the inverter. As examples of the latter cases to enhance the torque in higher speed range, several methods have been proposed, mainly for the PMSM drive systems ${ }^{(8)-(10)}$. In all methods, the induced voltage of the amateur reaction is controlled in principal to maximize the reluctance torque under the limited voltage condition.

\section{Applications for Downsizing and Higher Power Density}

3.1 Principal of the Downsizing and Higher Power Density of the AC Motor Drive System The electrical motor principally can generate mechanical power by the interaction between the current and the flux. The energy conversion is carried out in more narrow space than internal combustion engines. The density of the transmitted power by electric wires is much higher than the hydraulic or pneumatic hoses can transmit. In addition, the arrangement of the drive shafts limits the construction of drive trains and the transmitted power is limited either by the hydraulic or mechanical transmission. Electrical drive system provides more freedom of the arrangement of the drive train thanks to the flexible power transmission by the electric cables and higher power density of the electric motors. Especially, ac motor drive systems have the more benefits than the dc drive system thanks to the brushless structure and three phases ac power feeding.

3.2 Electric Ship Propulsions The arrangement of the ship propulsion equipments onboard becomes more flexible by the electrical propulsion system. Figure 5 shows a system configuration of the propulsion system for an icebreaker ship $^{(11)}$. ac drive system enables more precise torque control and can avoid the rush current at the ship starting by the fieldoriented control in the whole speed range ${ }^{(12)}$. This results in cutting the power margin for the rush current of the main motor and optimize the rated power of the traction equipment including the generator, traction circuit and main motors. In the case of the ship for the special mission such as an icebreaker for the southern polar observatory trip, high redundancy with

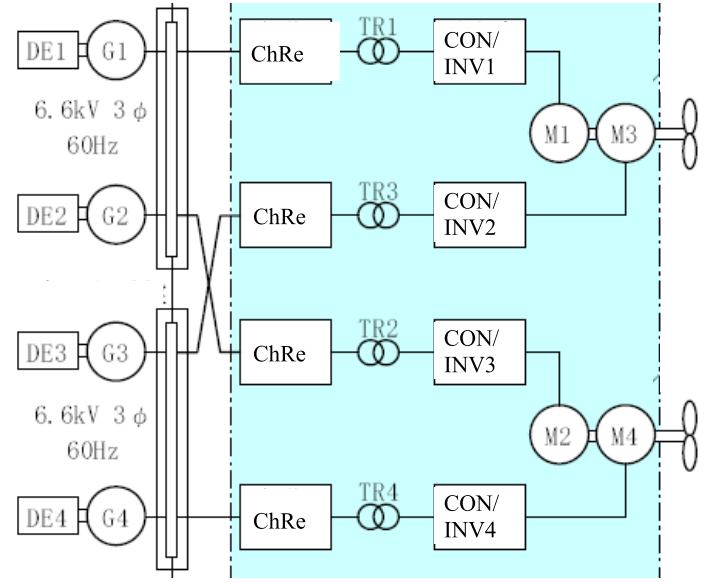

Fig. 5. System configuration of the propulsion system for an icebreaker ship ${ }^{(11)}$

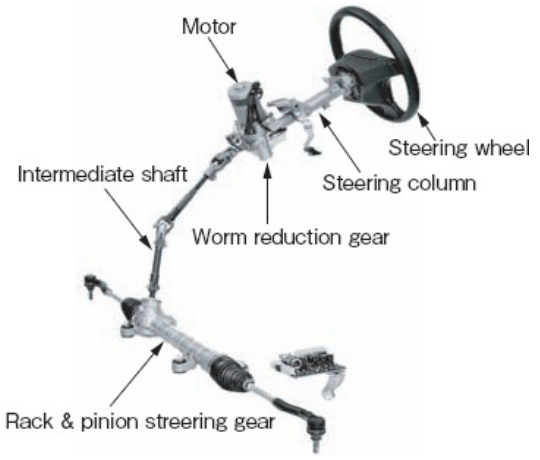

Fig. 6. System configuration of the electrical power steering ${ }^{(14)}$

the reliable ac motor drive system is much benefit on the applications.

3.3 Electric Power Steering For automobile steering systems, the hydraulic power steering are utilized for conventional power steering systems. Electric pumps are applied to some hydraulic power steering systems to obtain the pressured oil ${ }^{(13)}$. In electric power steering (EPS) systems, steering angle is amplified by brushless dc motors ${ }^{(14)}$. The EPS features more down sized and more energy efficient than the conventional hydraulic power steering systems. Figure 6 shows a column assist type EPS, which does not need any additional equipment such as an oil pump or a pressured oil supply hose. Recently developed EPS does not performs only a steering torque booster but an actuator to stabilize the vehicle motion and assist car's following the running lane ${ }^{(15)}$. As for stabilization of the car body motion, variable gear ratio function can changes the steering angle of front wheels against the steering wheel angle for the further more stable motion of car body. Steering assist control is studiedto secure the safely steering even if a motor cable fails in some phase ${ }^{(16)}$. The motor torque ripple and the cogging torque are evaluatedon EPSs design because drivers' feeling of steering is important ${ }^{(17)}$.

3.4 Elevator Applications Small-sized elevators are increasingly installed for residential homes, train passengers at stations, and pedestrians in midtown. In some cases, elevators are additionally installed while the facilities are in services. Some buildings do not have enough space to make 


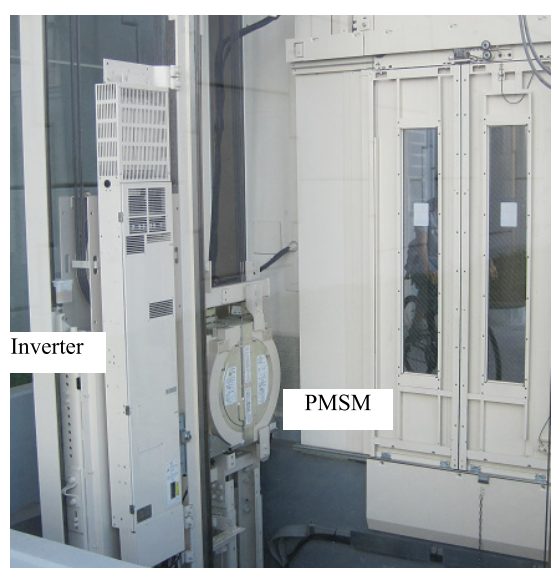

Fig. 7. Down sized PMSM drive system installed at elevator

machine rooms for the motors and inverters. In such cases, PMSMs drive system is preferable to be designed very thin and small and is installed in the same room of the moving cage, as shown in Fig. 7 which is an elevator for pedestrians in midtown. PMSMs can increase the current density in the stator winding, compared with induction motors under the same thermal design. PMSMs can be designed with less volume of the iron core by reducing the flux. More torque is expected in interior permanent magnet synchronous motors (IPMSMs) than surface permanent magnet synchronous motor (SPMSMs), because of the reluctance torque in addition to the PM torque. These result in increasing the efficiency of the PMSM and inverter both, by reducing current of IPMSM at the same torque as SPMSM. By utilizing the reluctance torque of IPMSM, the size of the system including control board, inverter and PMSM is reduced with $42 \%$ of their volume ${ }^{(18)}$.

\section{Applications for Higher Availability and Main- tenancebility}

4.1 Principal of the Higher Availability and Maintenancebility with AC Drive Systems Mechanical energy conversion system including internal combustion engines, hydraulic motors, hydraulic transmissions, and pneumatic actuators, sometimes needs periodical inspection and maintenance because they have frictional moving parts which are easy to be worn and oil seal parts which are easy to leak for oil. Electrical drive systems including variable speed ac motor drive systems require almost no inspections and less maintenance. Therefore, they can be more reliable or less chance of failure. This is originated from the principal that the contactless electro-magneto force is utilized for electrical and mechanical energy conversion. Thus, internal combustion engines or hydraulic actuators are replaced by ac motor drive systems in some application fields to reduce the maintenance work and to increase the reliability. With the recent improvement of reliability of the power electronics, thanks to IGBTs with the less loss and the simple drive circuit for instance, ac variable speed drive systems expand their application field up to $100 \mathrm{MW}$ class power range.

4.2 Hybrid Diesel Rail Cars For the quite same sake of hybrid automobiles, a fleet of diesel engine and lithiumion battery railway cars are utilized for non-electrified lines.

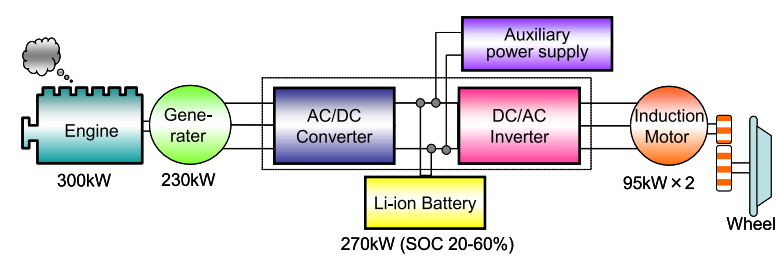

Fig. 8. Configuration of a diesel engineand Litium-ion battery hybrid traction system for rail $\mathrm{car}^{(19)}$

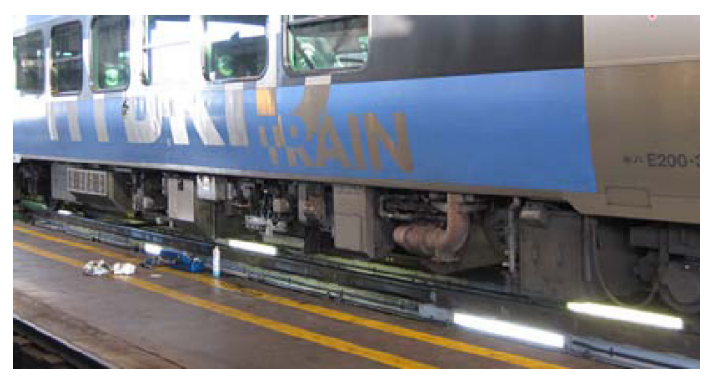

Fig. 9. Traction and auxiliary equipments onboard a hybrid diesel railcar

The hybrid traction system is so-called series hybrid system as shown in Fig. $8^{(19)}$. Series hybrid system has advantages against the parallel hybrid system ${ }^{(20)}$ such as more regenerative brake and less maintenance work due to eliminating a hydraulic transmission and a reduction gear. As shown in Fig. 9, the series hybrid rail car installs more traction and auxiliary equipments under floor than conventional rail cars with diesel motive units. Compact and light variable speed ac motor and generator system contributes the critical installation of the equipments in the limited space.

4.3 Large Scale Industrial Drive System In natural gas plants, compressors are originally driven by gas turbine engines, which requires more space to be installed, and frequent and long maintenance work. Large scale induction motor drive systems, for instance $100 \mathrm{MW}$ class, are recently applied to drive compressors to cope with these problems with the gas turbine engines ${ }^{(21)-(24)}$. Voltage source inverters are introduced to drive such size motors, instead of load commuted type inverters. Figure 10 shows a circuit configuration of large scale five-level inverter drive system, with three sets of star connected full bridge single phase 3 level inverters with GCTs, which works as a nine-level inverter across the line-to-line voltage. The specifications of a single inverter are $7200 \mathrm{~V}-2400 \mathrm{~A}-30 \mathrm{MVA}$ and three of the inverters with $120 \mathrm{VA}$ are for a motor. Water cooled system is applied to the inverter and its efficiency is $98.6 \%$. The power density reaches $1 \mathrm{MW} / \mathrm{m}^{3}$. Wave forms of a line to line voltage and a phase current is shown in Fig. 11. Almost perfect sinusoidal current wave is achieved, which contributes significantly to reduce the harmonics loss and EMC problems, and leakage current. This kind of motor drive system is achieved thanks to the evolution of power electronics and provides more reliable large power scale motor drive system.

Another variation of large scale motor drive system is the modular multi level (MMC) converter to drive fan or pump ${ }^{(25)}$. Figure 12 shows a MMC circuit configuration, which is originally applied to high voltage dc power transmission system. Each cell output zero voltage or $v_{c u j}$ and each phase voltage is 9 level output in this circuit. Lower 


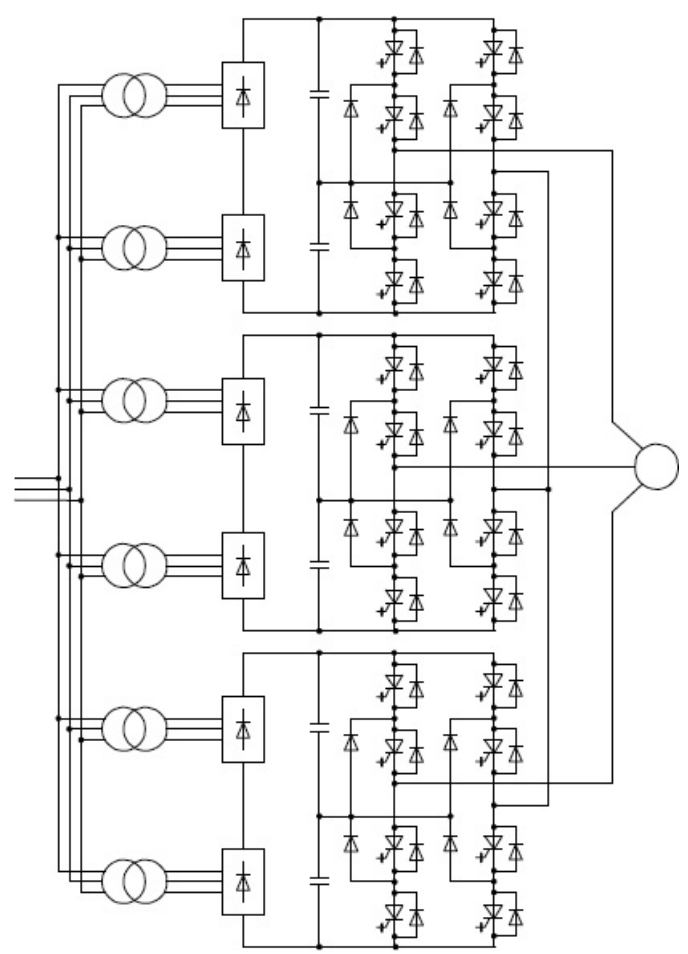

Fig. 10. Circuit configuration of 5 level inverter for large scale drive in gas and oil industry ${ }^{(22)}$
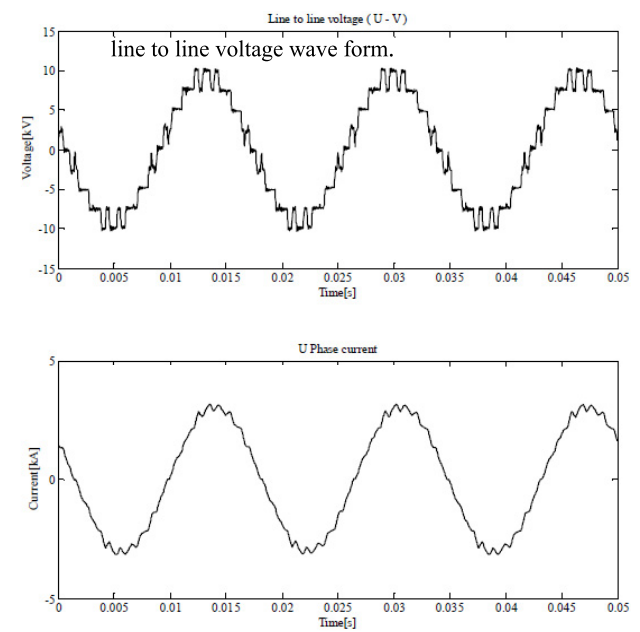

Fig. 11. Output voltage and motor current of 5 level inverter for large scale drive in gas and oil industry ${ }^{(23)}$

ac voltage with lower frequency, including dc voltage is impossible or hard to output in this circuit because the capacity of a capacitor in each cell is limited. To cope with the such problem in variable speed ac motor drive, a method to start induction motor with reducing the capacitor voltage to output lower phase voltage as shown in Fig. $13^{(26)}$. AC variable motor drive system with this circuit configuration promotes reliability and availability in large scale industrial drive systems.

4.4 Sensorless Motor Drive for Traction Applications

In railway vehicle and automobile traction applications, speed or angle sensorless drive system can provide more reliable and less maintenance systems. In addition the sensorless drive systems can be more down sized in the limited motor installation spaces. To drive inertial loads requires the higher
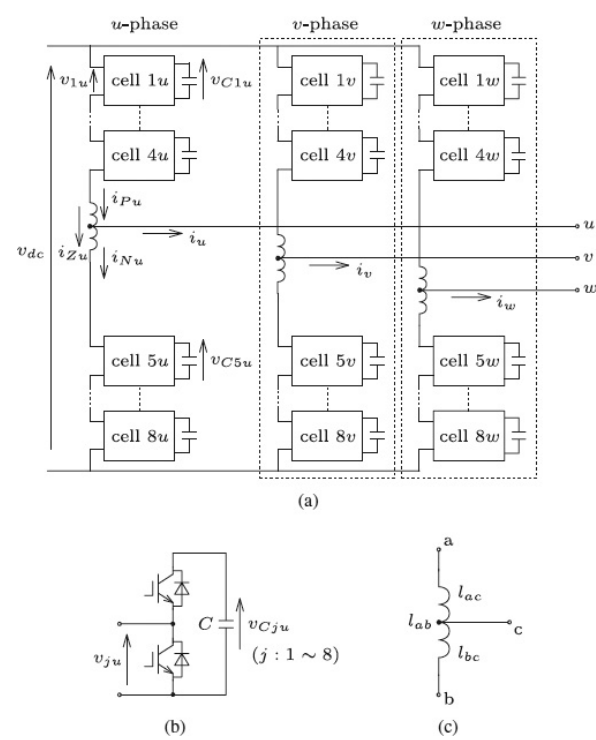

Fig. 12. Circuit configurations of $\mathrm{MMC}^{(25)}$

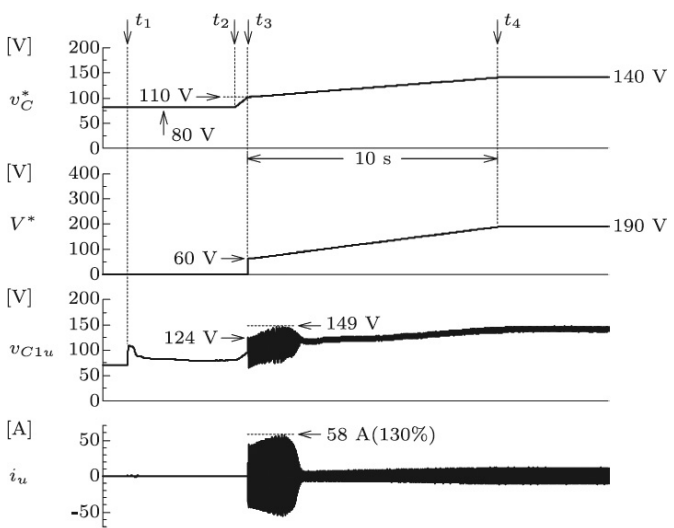

Fig. 13. A experimental test result to start induction motor with $\mathrm{MMC}^{(26)}$

torque in the ultra-lower speed range including zero speed and even in the reverse rotational condition. However, the induced voltage of the fundamental frequency is very low or zero in the speed region. Any additional information is required to estimate the angle or speed based on the current or voltage information. For induction motor, a mechanical simulator which calculates the rotor frequency based on the mechanical rotational equations is proposed to start the railway vehicle at zero speed ${ }^{(27)}$. The equivalent $\mathrm{V} / \mathrm{f}$ ratio is regulated along with the inertia and motor calculated torque based on the torque current. As shown in Fig. 14, an experimental test result is presented in which a railway vehicle can start even under the $200 \%$ of the rated load condition ${ }^{(28)}$.

As of IPMSMs, harmonics current or voltage injection is utilized for traction application for instance ${ }^{(29)}$. However the noisy sound due to the injected harmonics current comes a problem to deteriorate the comfort of passengers. In addition to the harmonics injection, a method to estimate pole position without harmonics voltage or current injection is proposed for IPMSMs at lower speed range ${ }^{(30)}$. In this method, differentiated stator current is detected while inverter output the zero voltage vector ${ }^{(31)}$. Utilizing the change of current is principally reasonable to detect the rotor angle information at 


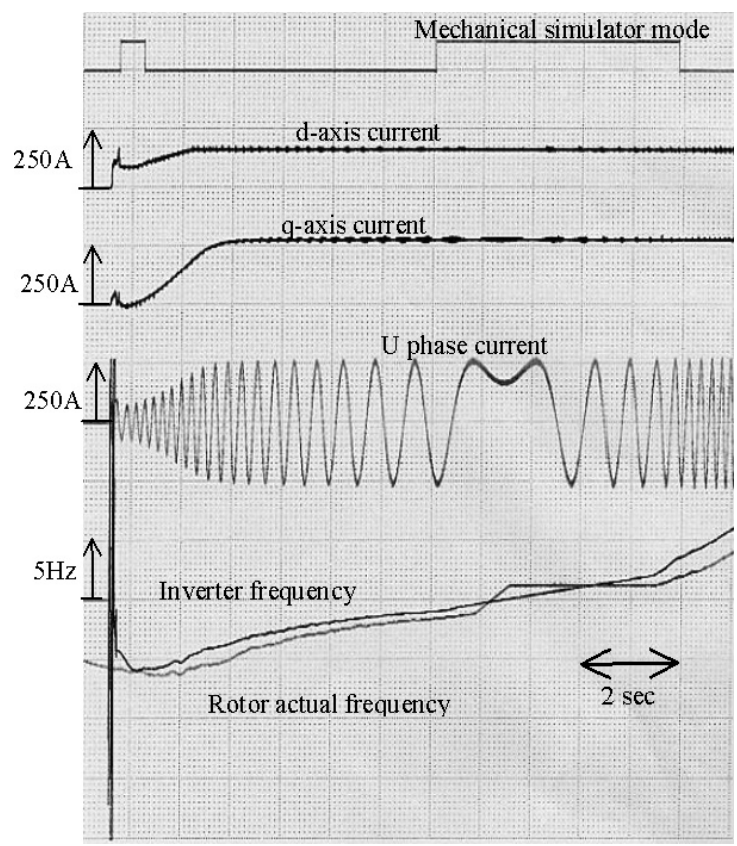

Fig. 14. An experimental result of IM starting with the mechanical simulator. ${ }^{(28)}$

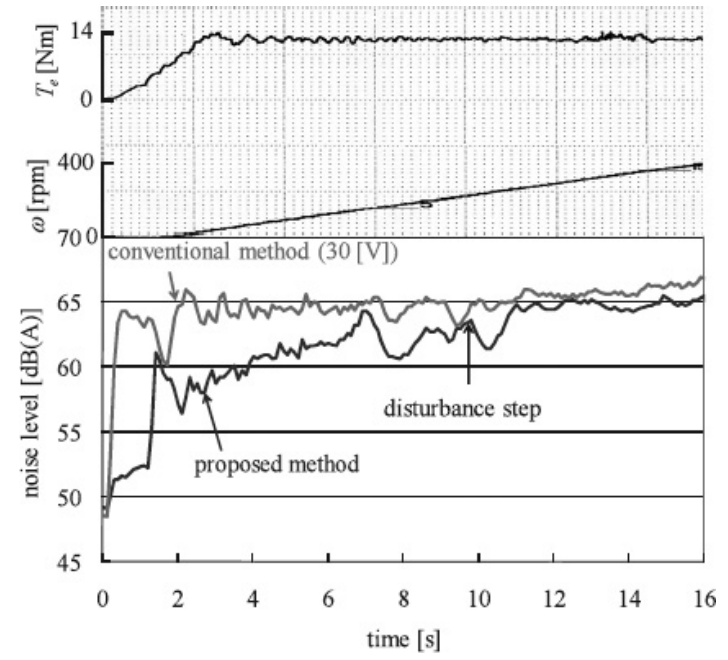

Fig. 15. An experimental test result of PMSM drive with lower noise harmonics injection ${ }^{(32)}$

lower speed range because the current of the fundamental frequency component reflect any rotor information. In the case of injecting the harmonics current, less injected current can prevent the noisy sound, but deteriorate the stable rotor angel estimation, especially at the transient of the motor current. A method to control the injected voltage to the IPMSM is proposed to reduce the noise ${ }^{(32)}$. The harmonics voltage is controlled according to the fundamental frequency component of stator current error and amplitude of the harmonics injected current. In Fig. 15, the proposed method successfully reduces the noisy sound and the angle estimation properly work.

The inverter starts switching operation in the motor rotating condition without any initial rotor speed or angle information, because the inverter operation halts during the vehicles coasting to save the inverter and the motor loses. As of induction motors, rotor speed can be principally estimated with the rotor flux induced voltage. On the other hand, the

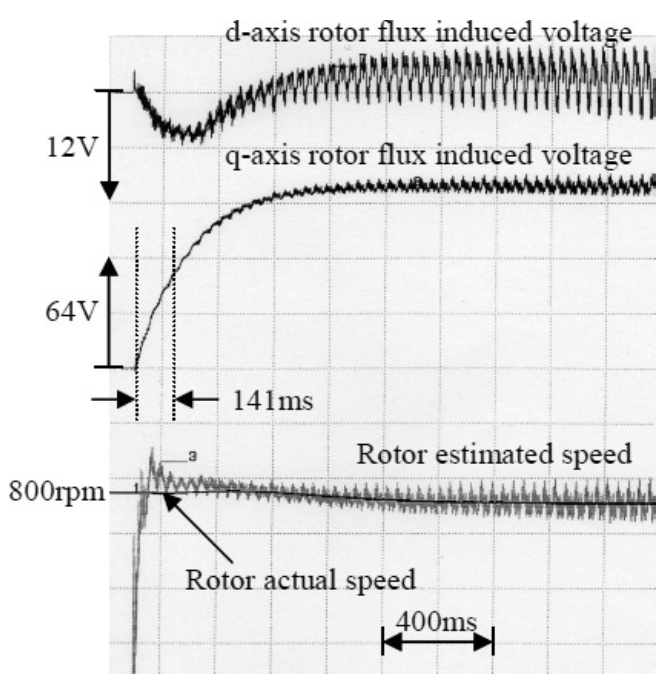

Fig. 16. An experimental tests result of IM starting at acoasting condition ${ }^{(33)}$
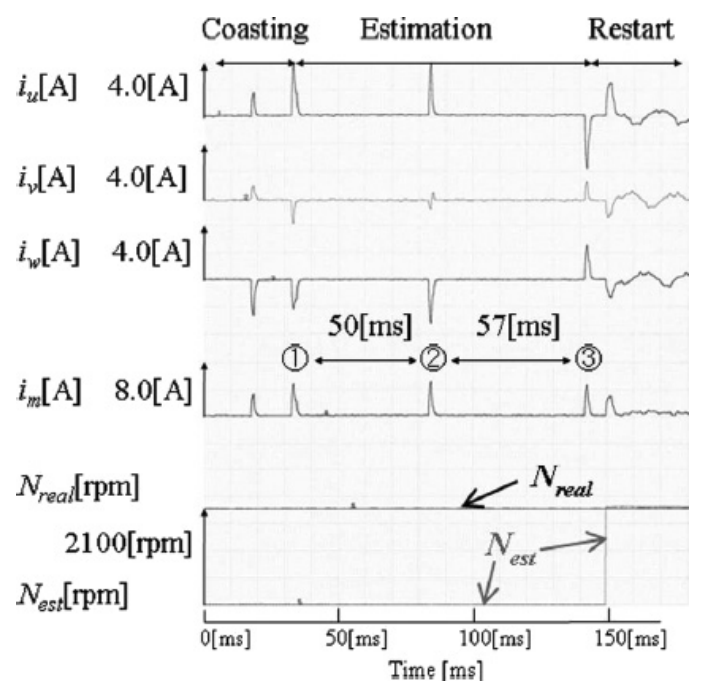

Fig. 17. An experimental test result of PMSM starting at a coasting condition ${ }^{(34)}$

rotor speed information is required to establish the rotor flux. Initial rotor speed estimation method with the punctual linearized method is introduced to design the controller systematically ${ }^{(33)}$. Figure 16 shows an experimental test result with a $1.5 \mathrm{~kW}$ rated induction motor to estimate the initial rotor speed. In the case of PMSMs, the inverter output voltage vector must be close to the PM induced voltage vector to avoid over current at the gate start under the rotor rotating condition. Three phase short circuit current vector is utilized to estimate the induced voltage vector angle to output the correct inverter voltage vector. The short circuit current vector is generated by outputting zero voltage vector of the inverter in several ms duration ${ }^{(33)}$. Detected short circuit current vector has error due to the delay of the control period. To compensate the error, rotor speed is calculated by the two intervals of short circuit vector angles. When the short circuit current vector 1, 2, and 3 are generated in Fig. 17, differences among their angles are detected to estimate the induced voltage vector angle and the estimated rotor speed $N_{\text {est }}$ can follow real rotor speed $N_{\text {real }}$ properly. 


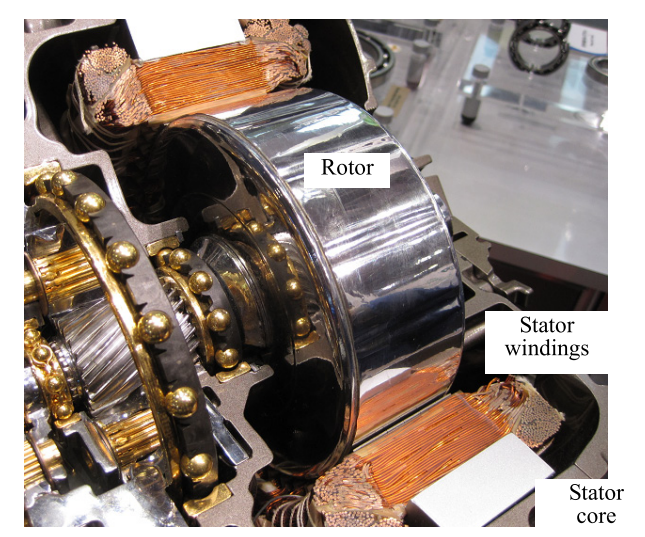

Fig. 18. Cut model of a $160 \mathrm{~kW}$ rating IPMSM for a HEV

\section{Energy Savings and Load Leveling Applica- tions}

\subsection{Principal of Energy Savings and Load Leveling by} Application of AC Drive Systems Regenerative operation is one the most advantage of the electrical and mechanical energy conversion by electric motors. This feature contributes to save the consuming energy and to reduce the maintenance work of mechanical drive system, especially when driving inertial loads, such as automobiles, railway vehicles and elevators. In addition, recent enhancement of energy storage devices, such as batteries and electro double layer capacitors (EDLCs), increases the effect of the energy savings and of leveling peaky load powers. Variable speed ac motor drive systems are most increasingly applied to the fields which are driven by internal combustion engines such as automobiles, diesel locomotives and ships. The downsized and higher power density features of ac motor drive systems also promote their application in these filed.

5.2 Automobile Traction and Other Ground Vehicles Applications For traction motors of the plug-in electric vehicles (PEVs) and hybrid electric vehicles (HEVs), IPMSM, as shown in Fig. 18, is mainly utilized due to their down sized and high efficiency features. The field weakening ratio is as three times high as the rated speed. The field weakening control and single pulse mode is applied as mentioned in section 2.4. Basic control strategy is same as the one for the railway vehicle traction with starting by the constant torque and field weakening control in the middle and higher speed range. The load profiles for automobile are more unpredictable and the dc voltage of the batteries changes wider than the case of the railway vehicle traction. These must be considered to determine the electrical and mechanical specifications of the motors for electric vehicles.

Similar applications are hybrid excavators and hybrid wheel loader. Hybrid excavators recover the kinetic energy of the turning upper structure by the generator and EDLCs, as shown in Fig. 19. The regenerated energy is used to assist the engine output power. This results in cutting $25-41 \%$ of fuel consumption compared to conventional hydraulic excavators ${ }^{(35)}$. A hybrid wheel loader is equipped with a series hybrid traction system, in which output power of diesel engine generator converted to dc power by a diode rectifier and the dc power is used to drive ac motors by a inverter.

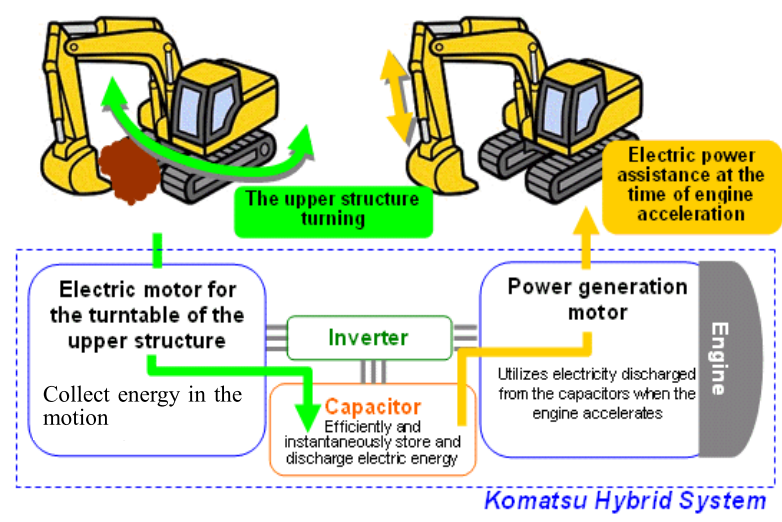

Fig. 19. A system configuration of a hybrid excavator $^{(35)}$

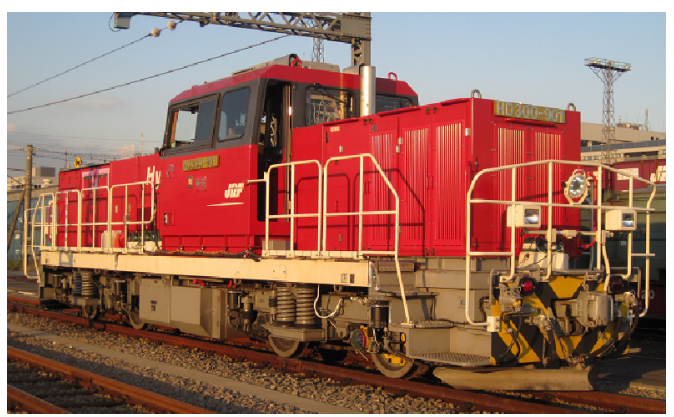

Fig. 20. Hybrid shunter locomotive type HD300

EDLC is connected to dc link circuit. This is a quite similar configuration of the ones for rail cars shown in Fig. 8. This configuration in the hybrid loader can improve the power conversion efficiency from the engine output power to the wheel output power by eliminating the hydraulic transmission. EDLCs charge the kinetic energy of the loader by the regenerative brake. The changed energy in EDLCs assists the output power of the engine generator to save both the fuel consumption and engine output power. The replacement of the hydraulic drive system by a variable speed ac motor drive system can improve the energy efficiency and save the fuel consumption.

5.3 Railway Shunter Locomotives Application In addition to the hybrid rail car described in section 4.1, series diesel engine and battery hybrid traction system is applied to a shunter locomotive too, as shown in Fig. 20, which switches freight cars at freight train stations ${ }^{(36)}$. The system configuration is quite same as the one for the rail car in Fig. 8, besides the engine output power and the battery energy. This system aims at load leveling for the diesel engines including the idle stop, because the load profile of the shunter locomotives is unpredictable and sometime the shunter locomotive must keep a stand by status for the possible work load. Thus, the load leveling contributes to cut much fuel consumption and much emission, and reduce the noise to start the locomotive.

5.4 Hybrid Turbo Charger for Ship Propulsion A hybrid turbocharger is applied to the large scale ship propulsion application. A permanent magnet synchronous generator (PMSG) is directly mounted on the turbine axle of the turbo charger, as shown in Fig. 21. The generator is driven by the exhaust gas energy of the diesel engine. The PMSG is a water cooled type $745 \mathrm{~kW}-9000 \mathrm{~min}^{-1}$ rating. The PMSG 


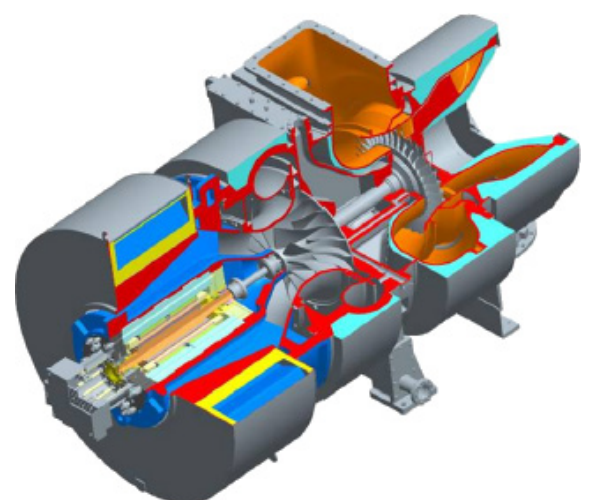

Fig. 21. A hybrid turbocharger for the ship propul$\operatorname{sion}^{(37)}$

is connected to an IGBT PWM rectifier and the inverters connected to the dc link circuit to supply the auxiliary power on board. The hybrid turbocharger is easy to be installed thanks to the compact size of the PMSG. The thermal energy of the exhaust gas is recovered and transmitted in higher efficiency by the electric power. In the lower rotational speed range of the diesel engine, the PMSG and the PWM rectifier work as PMSM and PWM inverter for an electric compressor of the intake air.This is thanks to the feature of a bidirectional energy conversion in the ac motor drive system.

\section{Conclusions}

Technical benefits of variable speed ac motor drive systems are roughly divided to two categories, which are a structural benefit and a functional benefit. The structural benefit such as downsizing and reliable operation is originated from higher power density of the flux in the iron core and current in the cupper, and brushless structure by feeding the ac power. The functional benefit such as higher torque control performance and bidirectional energy conversion is originated from the principal of the electrical and mechanical energy conversion by the Lorenz's force. At the first stage of the application, variable speed ac motor drive systems are mainly aimed at the structural benefit by replacing variable speed dc motor drive systems. This application is a replacement within the electrical and mechanical energy conversion. They are easy to obtain the electrical power source and with strong demand to the clean and highly controllable energy conversion. Thus, ac motor drive system has expanded their application field which aims at functional benefits. On the other hand recent ac motor drive systems are increasingly applied to the field which is categorized to the structural benefit. This is caused by the evolution of the structural aspect itself for instance higher power density and lower loss of ac motors and inverters. In addition, the restriction of the electrical power feeding is released than before thanks to the higher performance of energy storage devices for instance, Lithium-ion batteries. From these facts, variable speed ac motor drive systems must be enhanced in the simple structure, the cost reduction, and the higher performance to be an essential components as subsystem in the application systems in near future.

\section{References}

( 1 ) "Large scale servo drive motor", Yasukawa Technical Review, Vol.72, No.1, pp.1-2 (in Japanese)

( 2 ) A. Takenaka, H. Urushihata, S. Morino, M. Hattori, T. Inoue, and Z. Mashiki: "Development of a Variable Valve Timing System Controlled by an Electric Motor", DENSO TECHNICAL REVIEW, Vol.14, pp.24-29 (2009) (in Japanese)

( 3 ) S. Urababa, N. Sugimoto, S. Buma, S. Suzuki, A. Nishihara, and A. Taneda: "Development of the Electric Active Stabilizer Suspension System", Transactions of JSAE, Vol.38, No.2, pp.195-200 (2007-3) (in Japanese)

( 4 ) Y. Sawada and K. Kawakubo: "Low inertia and low noise dynamometer", MEIDEN JIHOU, Vol.316, No.5, pp.12-15 (2007) (in Japanese)

( 5 ) Y. Hojo, Y. Ohmori, K. Tanaka, and H. Ishiuchi: "Torque response characteristics of high response and high frequency inverter (VF66C)", TOYO DENKI REVEIW, No.123, pp.16-24 (2011)

( 6 ) Y. Nakazawa, S. Toda, and I. Yasuoka: "A New Vector Control for Induction Motor Drivesin Full Block Mode of Inverters", IEEJ Trans. IA, Vol.118, No.9, pp.1071-1080 (1998) (in Japanese)

( 7 ) Y. Kosaka, K. Takeda, S. Komiyama, and H. Iwano: "A study of reducing $\mathrm{CO} 2$ emissions for EV range in electric-motor vehicles", Proceedings on JSAE Autumn Annual Technical Meeting in 2008, No.92-08, pp.11-16 (in Japanese)

( 8 ) K. Yasui, Y. Nakazawa, and M. Mochizuki: "A Field Weaknening Control for PMSM of Hybrid Electric Vehicle", Proceedings of 2010 JIASC, (CD-ROM), 1-O4-3, pp.I-149-152 (2010) (in Japanese)

( 9 ) S. Kitamura and K. Kondo: "An enhanced torque control method of permanent magnet synchronous motor in the field weakening region", International Conference on Electrical Machines and Systems (ICEMS), 2010, pp.781-786 (2010)

(10) S. Makishima, K. Uezono, and M. Nagai: "Consideration of Motor Control Responses during Voltage Saturation of PWM inverter", IEEJ Trans. IE, Vol.130, No.5, pp.663-670 (2010) (in Japanese)

(11) K. Oono, K. Minakawa, and T. Nishikawa: "AC Drive Technology for Electric Propulsion Ship”, Proceedings of 2010 JIASC, (CD-ROM), 1-O4-4, pp.I153-156 (2010) (in Japanese)

(12) K. Oono: "Control of compatible power of electrical drive inverter", Journal of The Japan Institution of Marine Engineering, Vol.45, No.5, pp.43-47 (2010) (in Japanese)

(13) H. Jounokuchi, Y. Hmasaki, and Y. Yoshihara: "Technical Trends of Hydraulic-Electric Power Steering Systems", Koyo Engineering Journal, No.166, pp.13-18 (2004) (in Japanese)

(14) S. Kimura and S. Nakano: "Strategy for Transfer Elemental Designing and Employing Physical Characteristic Modeling of Steering Maneuvering (the Second Report)", TEKT Engineering Journal, No.1008, pp.22-29 (2010) (in Japanese)

(15) Y. Saito, H. Itoh, F. Ozaki, T. Nakamura, and S. Kawaji: "Design Method for EPS Control System Based on KANSEI Structure", IEEJ Trans. IA, Vol.130, No.2, pp.138-143 (2010) ( in Japanese)

(16) T. Nozawa, Y. Shintani, H. Tamaizumi, T. Hibi, and H. Itamoto: "Development of Brushless Motor EPS Assist Control for Disconnection Failure", JTEKT Engineering Journal, No.1008, pp.50-53 (2010) (in Japanese)

(17) Y. Morita, A. Yokoi, M. Iwasaki, H. Ukai, N. Matsui, N. Ito, N. Uryu, and Y. Mukai: "Improvement of Steering Feel of Electric Power Steering System with Variable Gear Transmission System Using Decoupling Control", IEEJ Trans. EIS, Vol.129, No.12, pp.2136-2143 (2009) (in Japanese)

(18) M. Kudo, H. Oya, S. Zatetsu, S. Karsten, M. Tanaka, and K. Nonaka: "Inverter for the elevator driveL1000A", Yasukawa Technical Review, Vol.73, No.2, pp.70-76 (2009) (in Japanese)

(19) M. Shiraki, H. Sato, and S. Arai: "A hybrid system for diesel railcar series Ki-Ha E200", Proceedings of International Power Electronics Conference (IPEC), 2010, pp.2853-2858 (2010)

(20) H. Ihara, H. Kakinuma, I. Sato, T. Inaba, K. Anada, M. Moromoto, T. Oda, S. Kobayashi, T. Ono, and R. Karasawa: "Development of Motor-Assisted Hybrid Traction System", Record of World congress of Railway Research (WCRR) 2006 (2008-5)

(21) H. Hosoda and S. Peak: "Multi-Level Converter for Large Capacity Motor Drive", IPEC2010, pp.516-522 (2010)

(22) D. Yoshizawa, K. Takao, M. Mukunoki, and Y. Shimomura: "The large Capacity 5 level GCT Inverter for OIL \& GAS plant application", Proceedings on JIASC 2008, No.1-79 (2008) (in Japanese)

(23) M. Nakamura, M. Tsukakoshi, and K. Hashimura: "Redundancy System for Continuous Driving Large Motor Drive Equipment", Proceedings of International Power Electronics Conference (IPEC), pp.2527-2530 (2010)

(24) M. Tsukakoshi, M.A. Mamun, K. Hashimura, H. Hosoda, and S.C. Peak: 
"Introduction of a Large Scale High Efficiency 5-level IEGT Inverter for Oil and Gas Industry", ECCE 2010, pp.4313-4320

(25) M. Hagiwara, K. Nishimura, and H. Akagi: "A Medium-Voltage Motor Drive with a Modular Multilevel PWM Inverter Part.I Experimental Verification by a 400-V, 15-kW Down scaled Model", IEEJ Trans. IA, Vol.130. No.4, pp.544-551 (2010)

(26) M. Hagiwara, K. Nishimura, and H. Akagi: "A Medium-Voltage Motor Drive with a Modular Multilevel PWM Inverter Part.II Startup Method and Performance", IEEJ Trans. IA, Vol.130, No.4, pp.552-559 (2010-4)

(27) T. Homma, S. Wakao, H. Shibuya, K. Kondo, Y. Sato, and T. Furuya: "A Stability Analysis of the Mechanical Simulatorfor Induction Motor Speed Sensor-less Controlin Ultra Lower Speed Range", Proceedings of the Eleventh IEEE Workshop on Control and Modeling for Power Electronics (COMPEL 2008), (USB Memory), COM220 (2008)

(28) K. Kondo and K. Yuki: "Study on an Application of Induction Motor Speed Sensor less Controlto Railway Vehicle Traction", IEEJ Trans. IA, Vol.125-D, No.1, pp.1-8 (2005) (in Japanese)

(29) H. Kawai, T. Sunohara, Y. Tasaka, and S. Fukasawa: "Permanent-Magnet Synchronous Motor Propulsion System for Tookyo Metro Ginza Line Trains", Toshiba Review, Vol.63, No.6, pp.46-49 (2009)

(30) Y. Shibano and H. Kubota: "Pole Position Estimation Method of IPMSM at Low Speed without High Frequency Components Injection", The IEEE Applied Power Electronics Conference and Exposition (APEC 2009)

(31) Y. Hosogaya and H. Kubota: "Consideration about Zero-Speed of Pole Position Estimation Method of IPMSM without High Frequency Components Injection", Proceedings on JIASC 2009, pp.I-605-606 (2009) (in Japanese)

(32) S. Taniguchi, T. Honma, S. Wakao, K. Kondo, and T. Yoneyama: "Control Method for Harmonics Voltage Injection to Achieve Noise Reduction in Position-Sensorless Control of Permanent-Magnet Synchronous Motors at Low Speeds", IEEJ Trans. IA, Vol.129-D, No.4, pp.382-388 (2009)

(33) S. Taniguchi, S. Mochiduki, T. Yamakawa, S. Wakao, K. Kondo, and T. Yoneyama: "Starting Procedure of Rotational Sensorless PMSM in the Rotating Condition", IEEE Trans. IA, Vol.45, pp.194-202 (2009)

(34) S. Taniguchi, K. Yasui, K. Yuki, and Y. Nakazawa: "A Free-run Startup Method for Position Sensorless PMSM", Proceedings on Technical Meeting of Motor Drive, Rotating Machineryand Semiconductor Power Conversion, RM-10-057. SPC-10-070. MD-10-002, pp.7-12 (2010)

(35) Komatsu News release: "Komatsu Introduces the World's First Hydraulic
Excavator: Hybrid Evolution Plan for Construction Equipment", http://www. komatsu.com/CompanyInfo/press/2008051315113604588.html (2012-2)

(36) T. Soeda, N. Terauchi, H. Nitta, G. Sugiyama, and T. Ogawa: "Development of a Hybrid Shunting Locmotive", The Proceedings on the 17th United Symposium on Railway Technologies (J-RAIL2010), No.SS3-2-2, pp.401-404 (2010-12) (in Japanese)

(37) K. Shiraishi, Y. Ono, and K. Sugishita: "Development of Large Marine Hybrid Turbochargerfor Electric Power Generation by Exhaust Gas from Main Engine”, Mitsubishi Heavy Industries Technical Review, Vol.47, No.3

Keiichiro Kondo (Senior Member) received B.S. and Ph.D. in the fac-

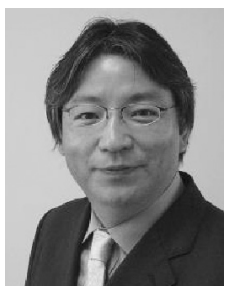
ulty of electrical engineering, department of science and technology, of Waseda University in 1991. He entered Railway Technical Research Institute in 1991 and 2000 respectively. Since 2007, Dr. Kondo is an associate professor of electrical and electronic engineering course of graduate school of Chiba University. His research interest is power electronics, AC motor drive, and their application to the railway vehicle traction. Dr. Kondo is a member of the Institute of Electrical Engineers of Japan. He is also a member of the IEEE Industry Applications, Industrial Electronics, and. He is a Dr.Eng. and Professional Engineer Japan (Mechanical Engineering, Technical Management).

Hisao Kubota (Senior Member) received the B.E., M.E., and Ph.D.

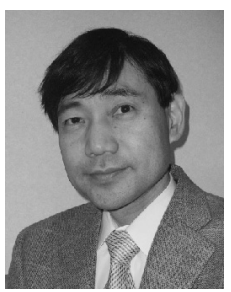
degrees in electrical engineering from Meiji University, Japan, in 1982, 1984, and 1989, respectively. Since 1984 , he has been a member of the faculty at Meiji University, where he is currently a Professor. His research interests are in motor drives. Dr. Kubota is a member of the Institute of Electrical Engineers of Japan. He is also a member of the IEEE Industry Applications, Industrial Electronics, and Power Electronics Societies. 